\title{
The Design of Reactor Internals Hold-Down Spring
}

\author{
Xue Guohong ${ }^{1, a}$, Zhang Ming ${ }^{1}$, Xie Linjun ${ }^{2}$, Yu Ching ${ }^{1}$ \\ 1 Shanghai Nuclear Engineering Research \& Design Institute, Shang Hai, China \\ ${ }^{2}$ Zhe-Jiang University of Technology, Hang Zhou, China
}

\begin{abstract}
Hold down spring(HDS), clamped between the upper support plate flange and the core barrel flange inside a pressurized reactor vessel, is used to provide a downward force to keep the core barrel stable and from being lifted off from the vessel ledge during reactor normal operation. Spring designer used to think under certain extreme operating conditions, the spring could be lifted off from the ledge because the spring is not stiff enough to prevent the "lift-off". Therefore, the spring was designed as stiff as it practically can be. However, finite element study indicated that the magnitude of preload is a strong function of friction coefficient. To find the magnitude of the friction coefficient, a series of tests were conducted on $1 / 10$ scale hold down spring samples of three different spring designs. From the test results, it was found that the friction coefficient increases rapidly as the number of loading cycles increases. This implies that the spring preload would increase rapidly during plant operation. Therefore, it is concluded that, because of the strong frictional effect, not only the current design is more than adequate, but also should be made even softer.
\end{abstract}

\section{Introduction}

In a pressurized water reactor (PWR), the core is contained inside a core barrel which is a cylindrical barrel with its top flange resting on the vessel ledge. The hold down spring (or HDS), which is a ring, resting on top of the core barrel flange, is compressed by the upper support plate flange which is, in turn, clamped down by the vessel head [1], as shown in Figure 1. The amount of spring compression is predetermined by the clearance between the thickness of the flanges plus the thickness of the spring and the distance between the vessel ledges [2].

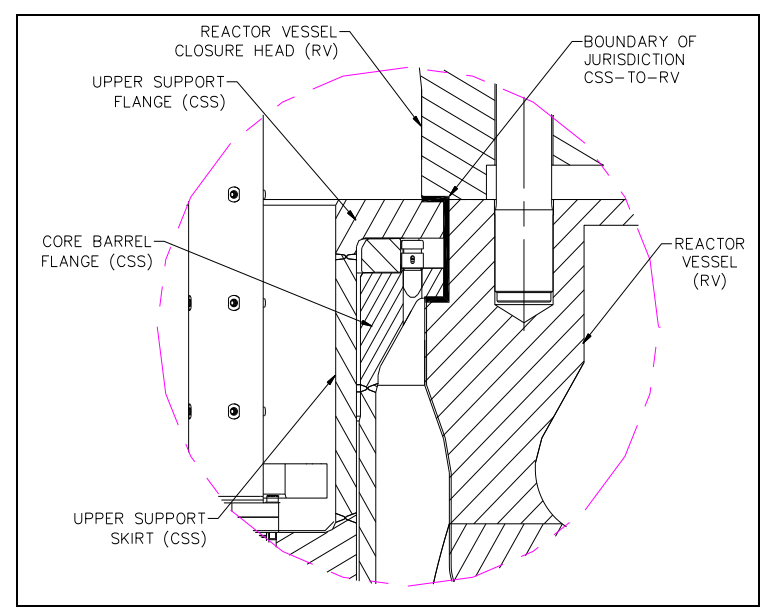

Figure 1. Reactor Internal-Hold Down Spring Configuration.

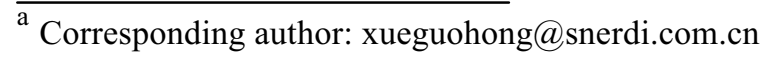

The design of the hold down spring has to meet two competing goals:

(1) The spring preload must be large enough to overcome any upward mechanical forces, such as the hydraulic, seismic and flow induced vibration forces, to keep the core barrel flange from lifted off from the vessel ledge. In other words, since the spring deflection is predetermined, the spring must be stiff enough to provide the downward force.

(2) The bearing stresses between the spring and the contacting flanges must be under a certain limit such that wear is not a problem. Otherwise, there is a potential problem that the preload could decrease because of the worn surfaces. This could lower the core barrel frequency and increase the vibration of the core assembly in the long run. In other words, the spring must not be too stiff.

In the real world, the hydraulic lift force exerting upward on the core barrel during normal operating is quite significant. Furthermore, the designers have to consider extreme transients such as the pump over-speed transient where as much as $44 \%$ more forces than the nominal lift forces could be exerted on the core barrel flange. In addition, the spring designers also have to consider other loads such as the seismic and the FIV loads which could occur, theoretically, simultaneously. With all the loads added up, the total could exceed 350 tons, generally speaking. In older plants, the HDS was designed to have a preload around 250 tons.

It is known that frictional force, parallel to the spring contacting surfaces, forms a counter-balancing moment against the moment generated by the lift forces, shown in

This is an Open Access article distributed under the terms of the Creative Commons Attribution License 4.0, which permits unrestricted use distribution, and reproduction in any medium, provided the original work is properly cited. 
Fig.2. However, the designer used to estimate the friction coefficient is around 0.3. Consequently, the friction forces were calculated to be relatively low. Therefore, the designers of the 3rd generation PWR plants, following the same line of thinking, made the spring stiffer to make up the in-adequacy.

The question is that friction coefficient of 0.3 being the right assumption? It is well known that the friction coefficient is difficult, if not impossible, to estimate because it is affected by a lot of factors, such as surface finish, contacting pressure, material, environment..., etc. Therefore, test is necessary to determine the magnitude of the friction coefficient.

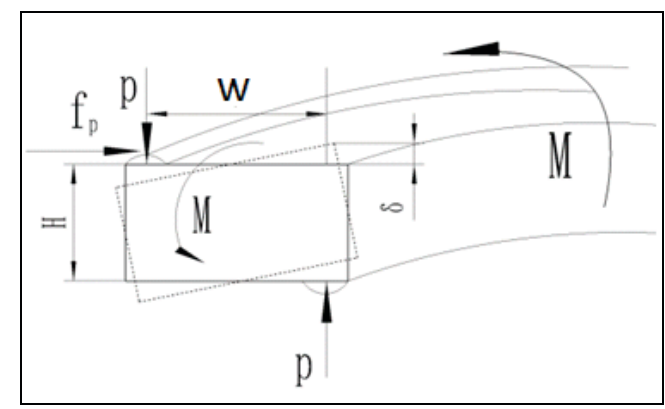

Figure 2. Counter-Balancing Frictional Forces

\section{Theoretical study}

\subsection{Force-deflection relationship}

The hold down spring is a circular ring with its cross section close to a rectangle. The initial preload force, $\mathrm{P}$, in the spring depends on the amount of compression and is obtained by considering the hold down spring as a narrow ring under distributed torque about its axis. The rotation of the section of the ring in its own plane about its centroid is given by [3].

For illustration purpose, the cross section of the hold down spring is presented in the following Fig. 3 where the "humps" are greatly exaggerated.

$$
\theta=M R_{\mathrm{m}}{ }^{2} / E I
$$

Where, $M$ is the uniformly distributed twist moment per linear length; $R_{\mathrm{m}}$ is the average radius of the spring from the centreline; $E$ is Modulus of Elasticity; $I$ is the moment of inertia for the structural section.

For small deflection, the rotation is given by $\theta=\delta / w$, Where, $\delta$ is the vertical deflection, $w$ is the distance between load application points; Therefore,

$$
M=P_{\mathrm{w}} / 2 \pi R_{\mathrm{m}}
$$

Where, $P$ is the preload force. Because of the close contact between the spring and the two flanges, frictional forces are expected to be counter-acting against the applied forces until slippage occurs. The moment generated by the frictional force can be written as:

$$
M_{\mathrm{f}}=\frac{P \mu h}{2 \pi R_{\mathrm{m}}}
$$

Therefore, the force-deflection relationship can be written as:

$$
P=\frac{2 \pi E I}{w(w-\mu h) R_{\mathrm{m}}} \delta
$$

In other words, the friction coefficient can be backed out once the force, $P$, and the deflection, $\delta$, are measured. It is also seen that the stiffness of the spring is inversely proportional to "w" which is the distance between the loading points. Since "w" is very close to the total width, "Wt", of the spring, the stiffness of the spring is also inversely proportional to the total width. In other words, if the spring were made wider, the spring would be softer.

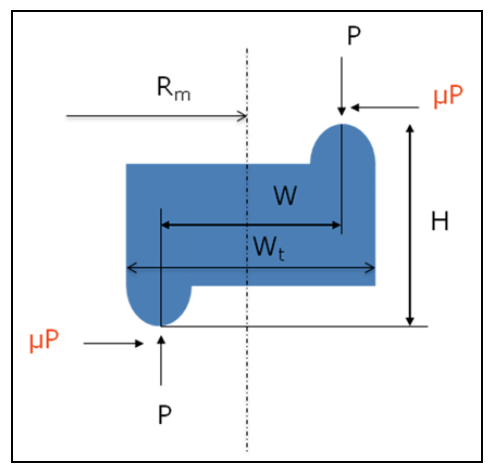

Figure 3. Counter-Balancing Frictional Forces

\subsection{Strain measurement}

Alternatively, the spring deflection can also be obtained by measuring hoop strain which can be converted into hoop stress because the hoop stress is related to the force, without derivation, by the following equation:

$$
\sigma_{\theta \max }=\frac{P(w-\mu h) h}{4 \pi I}
$$

And

$$
\delta=\frac{R_{\mathrm{m}} w(w-\mu h) P}{2 \pi E I}
$$

Consequently, friction coefficient can also be derived from the strain measurement.

\section{Analytical study}

The deflection-load-stress relationship of the spring was also studied using axis-symmetric finite elements in ANSYS, where the spring and portions of the core barrel and the upper support plate, including both flanges, were modelled, as shown in Fig.4. In addition, the contact and the target elements were used in the two interfaces between the spring and the flanges. Displacement input was put on the top of the upper support plate flange simulating the installed condition. 


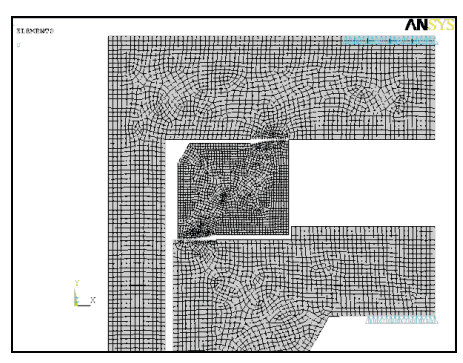

Figure 4. Finite Element Model of HDS

Fig. 5 shows the preload as a function of the spring height, $\mathrm{H}$, at different coefficients of friction. It is seen that when friction coefficient is low, 0.2-0.3, the preload, or the counter-balancing force, is moderate. When friction coefficient is high, for example $>0.6$, the counterbalancing force increases drastically. This implies that when the friction coefficient is high enough, the core barrel flange will not be lifted off from the vessel ledge.

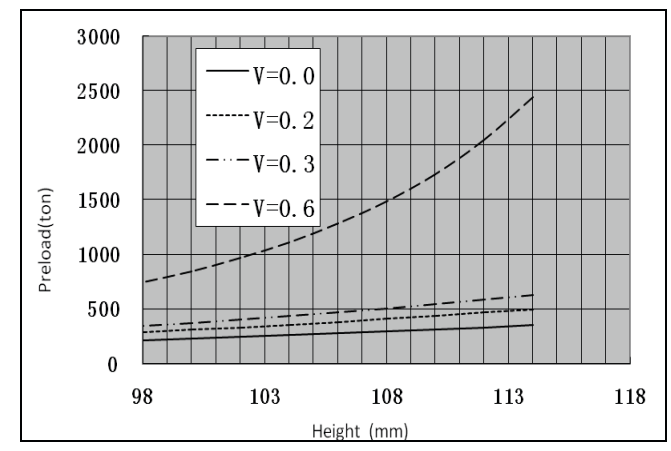

Figure 5. Preload as Function of Spring Height, at Different Coefficients of Friction

\section{Spring scale model test}

\subsection{Test method}

It is seen that the friction coefficient, $\mu$,can be derived from Equation (6), if force and deflection are measured. Alternatively, if force and hoop stress/strain were measured, the friction coefficient can also be calculated thru Eq.5.

The hold down spring test, sponsored by SNERDI, was carried out using $1 / 10$ scale samples in the testing facilities of Zhejiang University of Technology. The samples are of three different designs. Design A is the current design of the 3rd generation plants and is relatively stiff. Design $B$ is the current design of a future reactor which is relatively soft. Type $\mathrm{C}$ is an alternate design of Design B and is somewhat stiffer. Note that Design A is smaller in radius than either Design B or C. There were 3 samples of each spring design used in the test.

The hold down spring test was conducted on a RG4100 Microcomputer Control Electron Universal Testing Machine where the forces exerted on the test samples were controlled. The deflections and the strains of the spring are measured by extensometers and strain gages, respectively. Specifically, there were 4 extensometers installed at each of the 4 principal axes. At the same time, two strain gages were placed at each of the principal orientation $(0,90,180$ and 270 degrees), i.e., one on the lower inner surface and the other on the upper outer surface, as shown in Figure 6. It is noted that if the spring cross section were a true rectangle, the maximum hoop stress would all be equal at the 4 corners. Since the real cross section is slanted at the upper inner corner, it was decided, and is sufficient, to measure the strains at the two above mentioned corners.

It should be noted that since the measured strain is at the center of the strain gage, which has a width of $3 \mathrm{~mm}$ and since the maximum strain is at the top or bottom edge of the spring, the measured strain needs to be adjusted. The relationship between the measured and the maximum strain is $\sigma_{\max } / \sigma$ measured $=0.5 \mathrm{H} /(0.5 \mathrm{H}-1.5)$. Where “ $\mathrm{H}$ " is the cross sectional height of the spring.

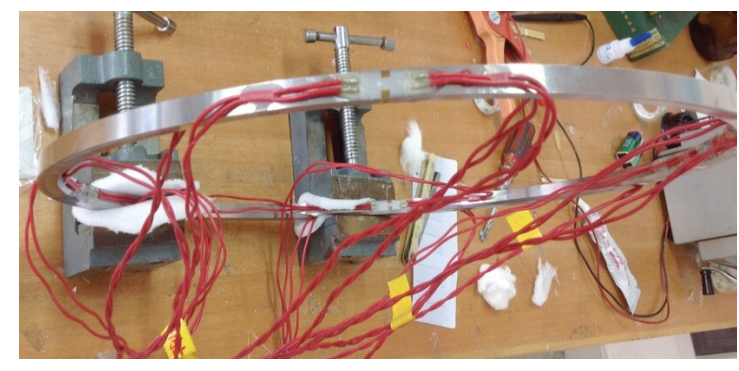

Figure 6. Strain Gage Installation

\subsection{Test sample}

The HDS samples are made of martens tic stainless steel, with Young's modulus of $195 \mathrm{GPa}$ at room temperature [4]. Both the upper and the lower flanges are made of $304 \mathrm{H}$ stainless steel. It is noted that all tests were conducted in room temperature. The static and the cyclic test are both tested in dry conditions. Later, a set of more limited static test was conducted in water to compare with the dry test results.

\subsection{Static test}

The purpose of the static test was to obtain the friction coefficient during initial preloading of the HDS. As stated above, the amount of deflection, which generates the initial spring preload is predetermined by the dimensional differences of components. The initial preload of the HDS in the older plants is generally around 250 tons. Therefore, for the static test, each sample was loaded up to $30 \mathrm{kN}$, which is equivalent to 300 tons for a full-size HDS.

The loading and unloading speeds were both set at 0.5 $\mathrm{mm} / \mathrm{min}$. Each loading/unloading process was repeated for a total of 3 times. After the data were collected, the spring was rotated 90 degrees and the process was repeated till all $0,90,180,270$ degrees were completed. In other words, for each sample, there are 12 data sets. A typical load-deflection relationship and a typical strainloading result from the static test is presented in Fig.7 and Fig.8. 
Based on the measurements from strain gages and the extensometers, the friction coefficients are averaged and summarized in Table 1 . It is noted that data taken at $20 \mathrm{kN}$ were also summarized in this table.

It is seen that based on the static tests, the friction coefficients are generally between 0.2 to 0.3 and is in the same range of what the original spring designers expected.

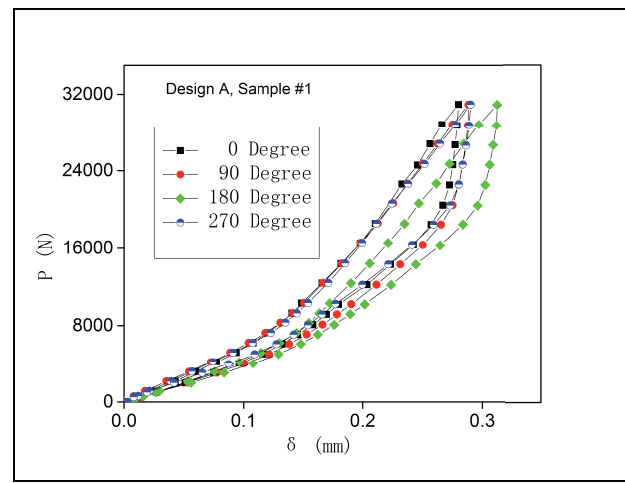

Figure 7. Load-Deflection Curve from Design A, Sample \#1, All 4 Rotations Load-Strain Curve from Design B, Sample \#1, 270-degree Rotation, 3rd Test, Inner and Outer Strain Gage Data

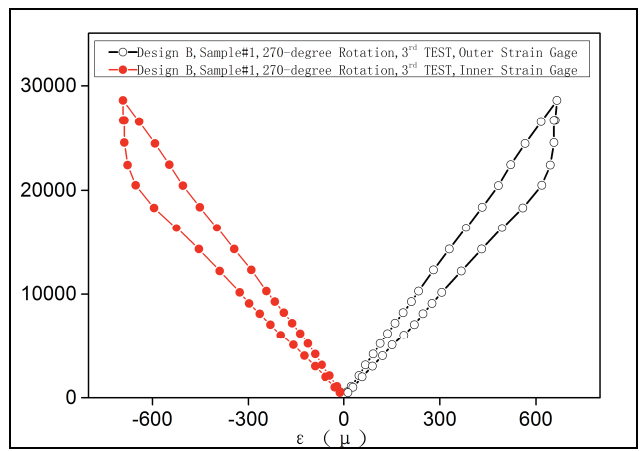

Figure 8. Load-Strain Curve from Design B, Sample \#1, 270degree Rotation, 3rd Test, Inner and Outer Strain Gage Data

Table 1. Summary of Friction Coefficients from Static Test

\begin{tabular}{|c|c|c|}
\hline \multirow{2}{*}{ Spring Design } & \multicolumn{2}{|c|}{ Friction $\mu$} \\
\cline { 2 - 3 } & $20 \mathrm{kN}$ & $30 \mathrm{kN}$ \\
\hline $\mathrm{A}$ & 0.28 & 0.30 \\
\hline $\mathrm{B}$ & 0.18 & 0.23 \\
\hline $\mathrm{C}$ & 0.23 & 0.26 \\
\hline
\end{tabular}

\subsection{Cycle Test}

The cyclic test was conducted on the sample \#1 of each design type after the static test. The purpose of the cyclic test is to simulate the accumulated effect of opening and closing of the reactor vessel head during refuelling for the entire 60 years of plant design life. Therefore, the number of cycles was conservatively set at 200 . Samples were loaded from zero to $28 \mathrm{kN}$ and unloaded back to zero. Data were recorded at cycle \#1, \#5, \#10, \#25, \#50, \#100, \#150 and \#200.

Typical results, where the strains measured have been converted to stresses, are shown in Fig.9.
It is seen that the hoop stresses increase significantly as the number of cycles progressed. In other words, the friction coefficient increases with the number of cycles. The final results are summarized in Table 2. Figure 10 and 11 shows the friction coefficient as a function of cycles for Design A and Design B.

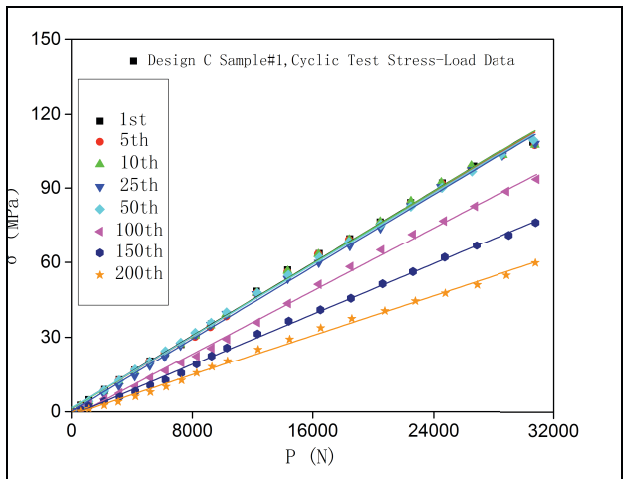

Figure 9. Stress-Load Relationship from Design C Sample \#1

Table 2. Friction Coefficient from Design B, Sample \#1

\begin{tabular}{|c|c|c|c|}
\hline \multirow{2}{*}{ Cycle \# } & \multicolumn{3}{|c|}{ Friction $\mu \mathrm{m}$} \\
\cline { 2 - 4 } & inner s.g & Outer s.g & Extensometer \\
\hline 1 & 0.248 & 0.216 & 0.271 \\
\hline 10 & 0.253 & 0.320 & 0.254 \\
\hline 25 & 0.359 & 0.319 & 0.386 \\
\hline 50 & 0.466 & 0.427 & 0.479 \\
\hline 100 & 0.506 & 0.483 & 0.560 \\
\hline 150 & 0.629 & 0.594 & 0.613 \\
\hline 200 & 0.634 & 0.622 & 0.662 \\
\hline
\end{tabular}

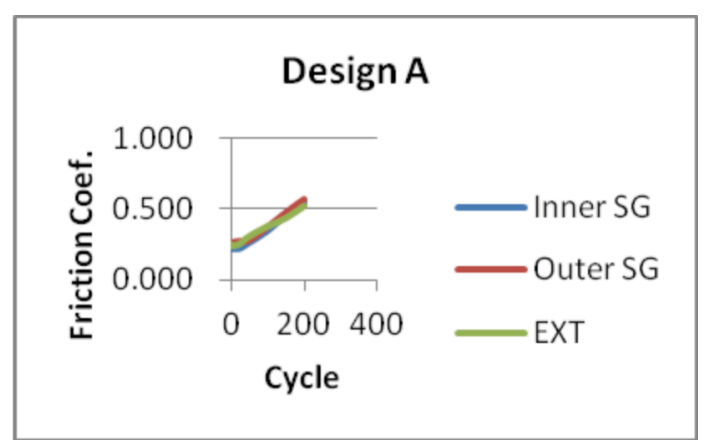

Figure 10. Friction Coefficient -Cycle Relationship for Design A Sample \#1

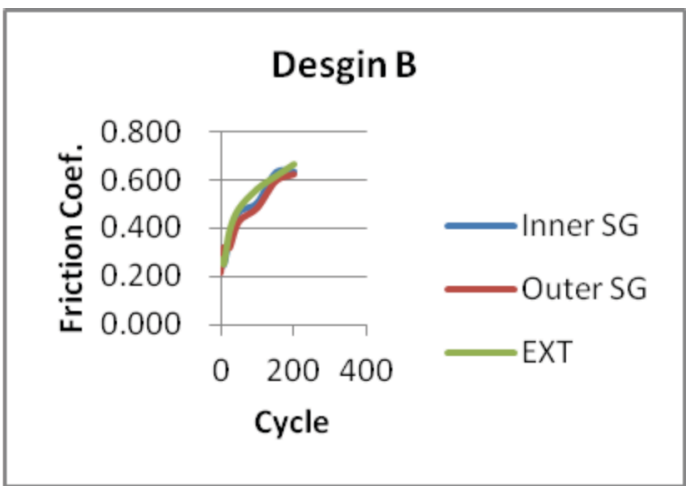

Figure 11. Friction Coefficient -Cycle Relationship for Design B Sample \#1 
After the cyclic tests, indentations were observed (as shown in Fig.12), not surprisingly, on the flanges which are made of stainless steel and are softer than the HDS. It is theorized that the indentations were made during the cyclic loading process and that microscopic, local, plastic deformation made the contacting surfaces binding and thus increased the frictional effect.

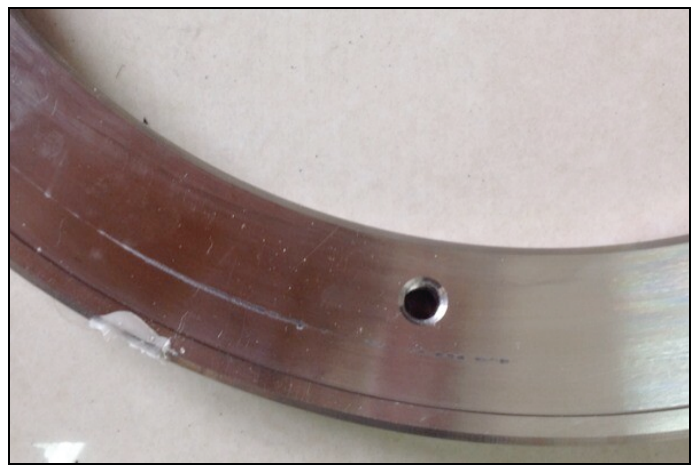

Figure 12. Indentations on Bottom Flange After Cyclic Test

\subsection{Spring-flange matching test}

Because the friction coefficient was observed to be increasing drastically with the number of cycles during the cyclic test, it is decided to carry out another set of tests where new spring was paired with used flanges and vice versa, noting that "new" simply means the part has not undergone cyclic test and "used" means the contrary. The procedure for this test was identical to the static test described above. Fig.13 and 14 show the comparison of load-deflection relationship between "new-used" and "new-new" for Design A and C, respectively.

It is seen that the new spring-used flange pair is significantly stiffer than the new spring-new flange pair. Furthermore, from Figure 15, it is obvious that the "usednew" pair is not much different from the new-new pair. Therefore, this part of the test reconfirms the thought that the indented flange affects the load-deflection process which, in turn, resulted in the increase of friction coefficient.

On the other hand, since the spring samples were made of martens tic stainless steel, which is much harder than the matching 304 stainless steel, the surfaces were not indented. Therefore, there is no effect on the friction coefficient.

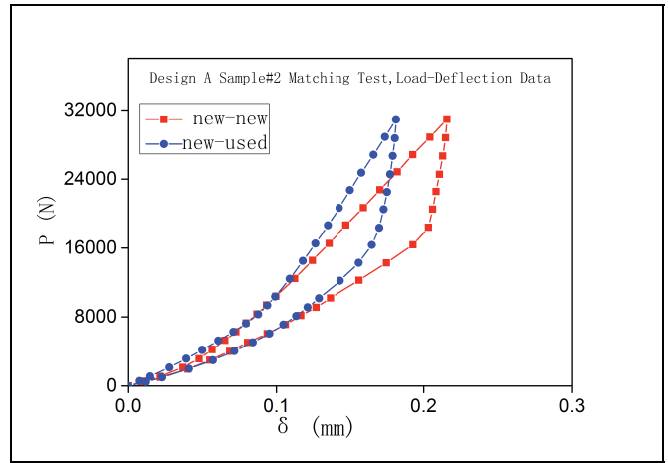

Figure 13. Comparison of Load-Deflection Relationship between "new-used" and "new-new" for Design A.

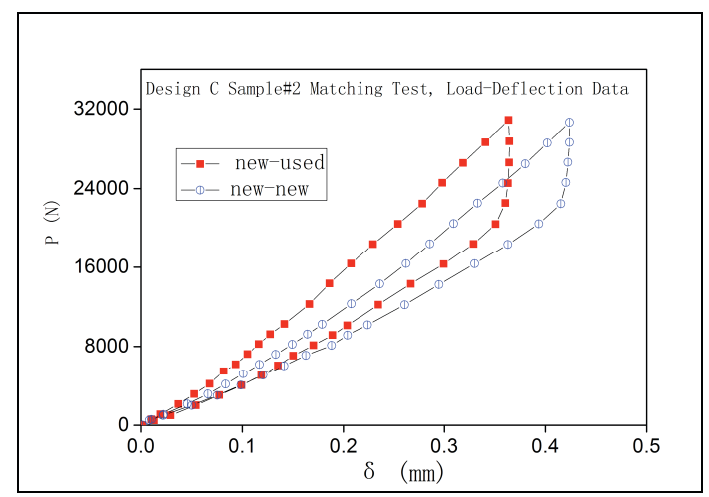

Figure 14. Comparison of Load-Deflection Relationship between "new-used" and "new-new" for Design C

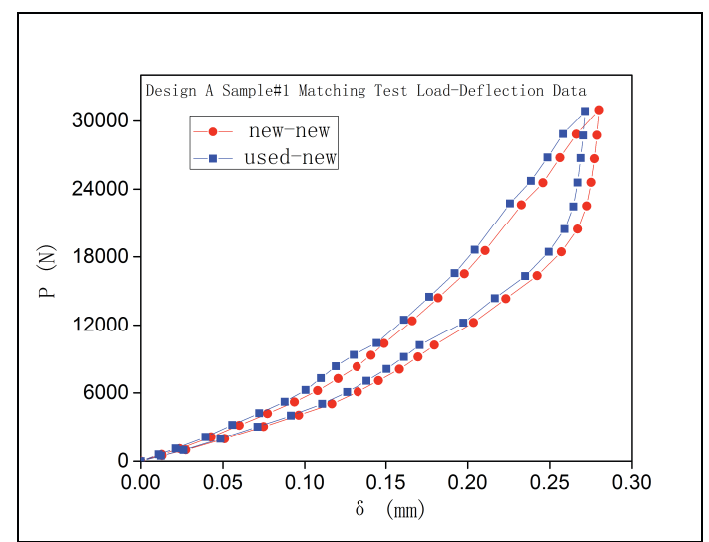

Figure 15. Comparison of Load-Deflection Relationship between "used-new" and "new-new" for Design A

\subsection{In-water static test}

The in-water static test was simulated by adding water continuously into the assembly which is sealed off by glue. The test was conducted with the sample\#3 of each design after the in-air static test. The samples were loaded, same as the in-air tests, up to $30 \mathrm{kN}$. An example of the load-hoop stress relationship is shown in Fig.16.

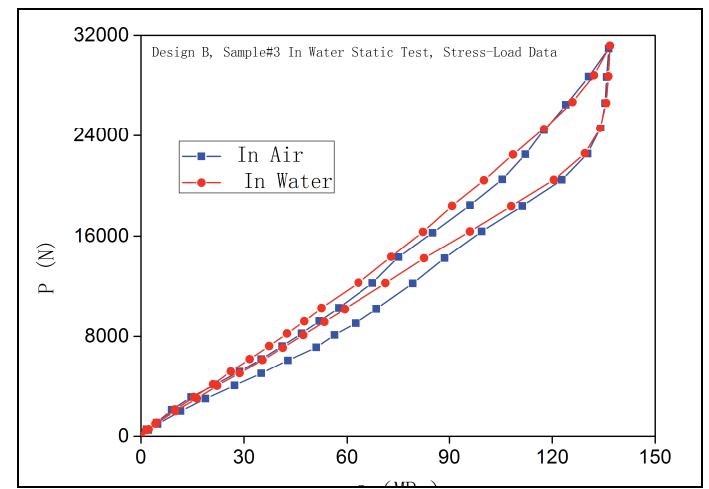

Figure 16. Load-Hoop Stress

As the summary results shown in Table 3 , there is essentially no difference between the in-air and the inwater data. Therefore, it can be concluded the in-water 
environment has no significant effect on the friction coefficient.

Table 3. Comparison of Friction Coefficient In Water and Air

\begin{tabular}{|c|c|c|c|c|}
\hline \multirow{2}{*}{ Spring Design } & \multirow{2}{*}{ State } & \multicolumn{3}{|c|}{ Friction $m \mathrm{~m}$} \\
\cline { 3 - 5 } & & Inner & Outer & EXT \\
\hline \multirow{2}{*}{ A } & In Air & 0.34 & 0.37 & 0.28 \\
\cline { 2 - 5 } & In-WAT & 0.34 & 0.34 & 0.28 \\
\hline \multirow{2}{*}{ B } & In Air & 0.27 & 0.33 & 0.23 \\
\cline { 2 - 5 } & In-WAT & 0.24 & 0.22 & 0.25 \\
\hline \multirow{2}{*}{ C } & In Air & 0.26 & 0.23 & 0.25 \\
\cline { 2 - 5 } & In-WAT & 0.26 & 0.30 & 0.24 \\
\hline
\end{tabular}

\section{Conclusion}

From these tests, it can be concluded that friction between the contacting surfaces, not pronounced at the beginning, increased rapidly as the number of cycles increased. Since the hold down spring is under cyclic flow induced vibration loads during plant normal operation, the same frictional effect can be expected in real plant situations. Consequently, the spring can be made softer and the initial preload on the spring can be set relatively low. This is because that, after a short time of normal operation, the frictional effect would be sufficient to counterbalance any additional lifting loads acting on the core barrel flange and to keep it from lifting-off. The benefit of a softer spring, at the same time, is the lessening of the wear between the contacting surfaces.

\section{References}

1. Zheng Ming-Guang, Pressurized Water Reactor Nuclear Power Plant Engineering Design, 91(2013)

2. Zhangzhai, Nuclear techniques.J.E.36,(61-68) 2013

3. Young,W.C. \& Budynas, R.G, Roark's Formulas for Stresses and Strain, (220-221) 1965

4. ASME Boiler and Pressure Vessel Code, Section II, Part D, 776-778 (2007) 